\title{
COLD AND WARMTH VASOCONSTRICTOR RESPONSES IN THE SKIN OF MAN
}

\author{
BY \\ J. GRAYSON \\ From the Department of Physiology, The University of Bristol \\ Received June 12, 1950
}

The increase in peripheral blood flow that follows the application of heat to the body is brought about in part by a purely nervous mechanism initiated in the skin, and in part by the central action of circulating warmed blood (Pickering, 1932). The author has recently analysed in detail the separate parts played in peripheral vasodilatation by rising environmental temperatures and by rising body temperatures (Grayson, 1949). The experimental subjects were mainly healthy men students, and a heating cabinet was used in which they sat with head and right arm outside; blood flows were measured by venous occlusion plethysmography in the fingers and forearm of the right arm. It was thus possible to correlate accurately peripheral blood flow with ambient temperature. Three phases were described in the responses of the finger circulation to rising cabinet temperatures.

(1) During the early stages of body heating, an increase occurred in the skin blood flow, most marked between cabinet temperatures of $28^{\circ}$ and $36^{\circ} \mathrm{C}$.; at the same time the rectal temperature fell or remained steady.

(2) As the cabinet temperature rose above $36^{\circ} \mathrm{C}$. a significant drop in blood flow occurred.

(3) After prolonged exposure of the subject to temperatures of $40^{\circ} \mathrm{C}$. or over, the rectal temperature rose, perspiration began, and the skin blood flow rose to a final equilibrium.

Further investigation made it clear that the low blood flows seen where the cabinet temperature was below $28^{\circ} \mathrm{C}$. were the result of reflex vasoconstriction initiated at the body surface by exposure to an environment colder than the body. The vasodilatation seen in the first phase of the triphasic response was thus brought about by removing external stimulus of cold. The vasoconstriction seen in the second phase was shown to be a reflex response initiated at the body surface by exposure to temperatures hotter than that of the body. Reflex vasoconstriction to cold or heat could both be regarded as protective reactions in the presence of unfavourable environmental temperatures. The final vasodilatation following prolonged exposure to high temperatures always accompanied a rise in rectal temperature, and it was thought that this part of the response might well be brought about by circulating warmed blood. The efferent pathway for all these reactions was shown to be in the sympathetic nerves.

In the above investigation, 57 experiments were carried out on 53 subjects, none of them suffering from obvious circulatory disease; 48 subjects gave the reactions to heating just described. In the other 5 subjects and a further 5 cases of Raynaud's disease and acrocyanosis, curves of a different type were obtained. The investigation of these abnormal findings and a further elucidation of the factors underlying normal vasoconstrictor responses to cold and heat forms the basis of the present work.

\section{MeTHODS}

In the experiments just described, a thermostatically controlled heating cabinet was used in which the subject sat with his head and right arm protruding and exposed to the room air at $20^{\circ} \mathrm{C}$. Blood flow changes in the fingers were recorded using a venous occlusion plethysmograph of a 
type first suggested by Professor A. A. Harper, and described in detail elsewhere (Grayson, 1949). In most of the 57 experiments referred to, the plethysmograph was used in a water bath at $31^{\circ} \mathrm{C}$. and sealed to the hand with the metacarpal heads enclosed. Under these conditions, with intensive body heating, the maximum recorded blood flows were usually about $15.5 \mathrm{ml} . / 100 \mathrm{ml}$. of tissue/min. In 17 of the experiments, the same type of plethysmograph was used without the water bath and sealed to the hand at the base of the fingers by means of vaseline bandages. The maximum blood flows were now about $26.5 \mathrm{ml} . / 100 \mathrm{ml}$. of tissue/min. The difference was shown to be largely due to the greater volume of non-expansible tissue within the plethysmograph when the metacarpal heads were included. The results with both types of recording were, however, qualitatively similar.

An additional 40 experiments have been recently performed in which the skin temperature of the right index finger was used as the index of the blood flow change. In these experiments, stimulus of cold was removed from the surface of the body by covering it with blankets. Skin and rectal temperatures were recorded thermoelectrically using moving-coil mirror galvanometers and a manually operated mechanical device to follow the movement of the light beam and give a continuous kymograph record of the temperature changes (Schmidt and Pierson, 1934). When all the body was covered, the temperature of the abdominal skin under the blankets rose rapidly and usually reached equilibrium levels of about $35^{\circ} \mathrm{C}$. within 10 minutes. Thereafter, the cold and warmth vasoconstrictor responses were elicited by exposing different areas of the body surface to different temperatures.

\section{RESULTS}

During heating experiments using the cabinet, the response of the finger circulation to changes in environmental temperature was usually rapid. A sudden rise in cabinet temperature anywhere in the range of $20^{\circ}$ to $36^{\circ} \mathrm{C}$. usually produced rapid vasodilatation, whereas a fall in cabinet temperature below $36^{\circ} \mathrm{C}$. produced equally rapid vasoconstriction.

\section{Delayed Vasodilatation. During Heating Experiments}

In five apparently healthy students, results were obtained that differed from those described. In experiments on these subjects, using the cabinet, no vasodilatation occurred in the skin (Fig. 1) during the first 90 minutes of heating when the ambient temperature rose from $20^{\circ} \mathrm{C}$. to about $40^{\circ} \mathrm{C}$. The hands remained cold, pale and dry, and the rectal temperature remained steady or fell. During the last 30 minutes, when the cabinet temperature was higher than $40^{\circ}$. C. the rectal temperature rose. At the same time perspiration began and the blood flow in the fingers increased, the final blood flows reached being similar to those obtained in normal subjects (Table I).

TABLE I

Cold Hypersensitivity in Non-Pathological SubJects

\begin{tabular}{|c|c|c|c|c|c|c|c|c|c|}
\hline & $\begin{array}{l}\text { Case } \\
\text { No. }\end{array}$ & 20 & 25 & $\begin{array}{c}\text { Cabine } \\
30\end{array}$ & ${ }_{35}^{\text {Temp }}$ & $\begin{array}{c}\text { ures i } \\
40\end{array}$ & C. ${ }_{45}$ & 50 & \multirow{6}{*}{ 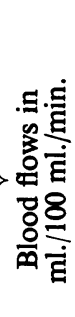 } \\
\hline \multirow{3}{*}{$\begin{array}{l}\text { Air- } \\
\text { filled }\end{array}$} & 1 & 0.5 & 1.0 & 0.5 & 05 & 1.0 & $12 \cdot 5$ & $18 \cdot 0$ & \\
\hline & 2 & & thar & & 1.0 & 1.0 & $10 \cdot 6$ & - & \\
\hline & 3 & $2 \cdot 3$ & $2 \cdot 2$ & $2 \cdot 6$ & 2.9 & $3 \cdot 2$ & $12 \cdot 9$ & $27 \cdot 9$ & \\
\hline \multirow{2}{*}{$\begin{array}{l}\text { Water- } \\
\text { filled }\end{array}$} & 4 & 3.0 & 2.5 & $2 \cdot 0$ & $2 \cdot 2$ & $5 \cdot 2$ & $10 \cdot 3$ & $15 \cdot 2$ & \\
\hline & 5 & $6 \cdot 0$ & $5 \cdot 5$ & $6 \cdot 3$ & $5 \cdot 5$ & $9 \cdot 2$ & $13 \cdot 3$ & - & \\
\hline
\end{tabular}

Detailed questioning produced evidence in one case of numb and painful fingers in cold weather, and of frequent chilblains affecting the feet. In another where the hands were cold and cyanotic when exposed to the cold, chilblains affected alike the feet, hands and nose. One of the others 
gave a doubtful history of chilblains in childhood. In the other two there was no history or clinical sign suggesting circulatory abnormality.

Delayed Vasodilatation in Raynaud's Disease and Acrocyanosis.-Four cases of Raynaud's disease and one of acrocyanosis were examined pre-operatively using the heating cabinet as described above. In all cases delayed vasodilatation of the kind already described was found, the blood flow in the fingers remaining low until after the rectal temperature had risen. The maximum blood flows finally recorded were normal.

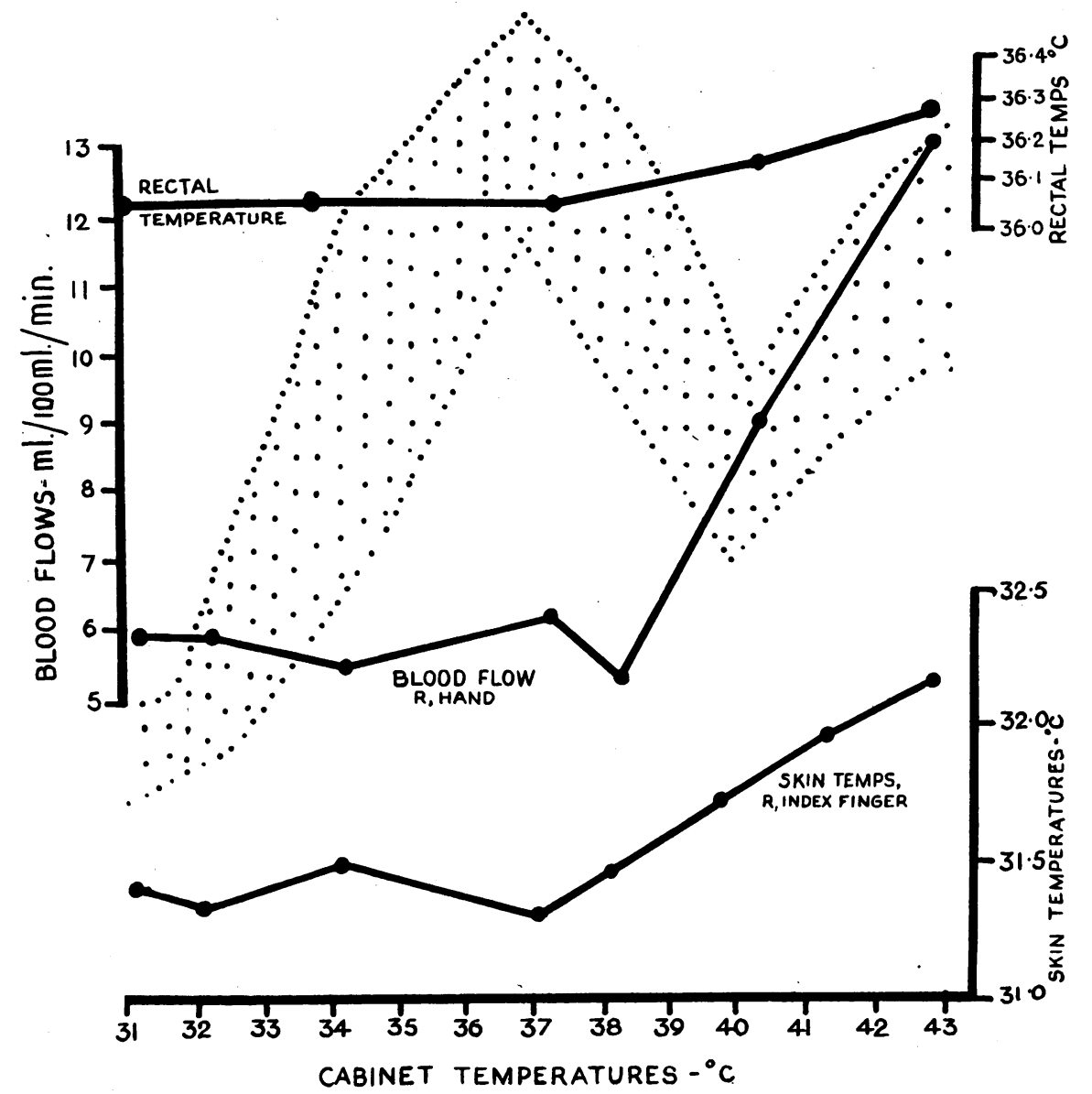

FIG. 1.-Delayed cutaneous vasodilatation in response to rising environmental temperature-_" healthy " subject. The shaded area represents the limits of normal for blood flows in the series.

\section{EXPERIMENTAL EVIDENCE OF COLD HYPERSENSITIVITY}

It seemed possible that these abnormal findings, even where there was no clinical history to suggest it, might be the result of individual circulatory hypersensitivity to cold. This could be a local fault similar to that described in Raynaud's disease (Lewis, 1936), or might be more generalized. Additional experiments were consequently performed on certain of the subjects.

The Effect of Reducing Local Cold. Using the heating cabinet and plethysmographic recording of blood flow, a subject who had previously manifested typical delayed vasodilatation was exposed to rising environmental temperatures with the water in the plethysmograph at $31^{\circ} \mathrm{C}$., and subsequently at $34^{\circ} \mathrm{C}$. In both experiments the head and right arm were exposed to the room air at 
$20^{\circ} \mathrm{C}$. and the blood flow remained at less than $4 \mathrm{ml} . / 100 \mathrm{ml} . / \mathrm{min}$. until the cabinet temperature reached $41^{\circ} \mathrm{C}$. Vasodilatation did not begin until after the rectal temperature had risen, the final blood flow reached on both occasions being $14.5 \mathrm{ml} . / 100 \mathrm{ml} . / \mathrm{min}$.

Similar results were obtained with another subject examined with the water bath at $31^{\circ} \mathrm{C}$. and again at $34^{\circ} \mathrm{C}$. Thus, where delayed vasodilatation occurred in response to body heating, the results were not altered by local temperature.

The Effect of Reducing the Total Area of Body Exposed to Cold. The cabinet temperature was raised before the experiment to $35.0^{\circ} \mathrm{C}$. (Fig. 2A). The subject sat inside and for 25 minutes finger blood flows were recorded from the right hand. More of his right arm was then enclosed within the cabinet and the blood flow observations repeated. Finally, the head and neck were totally enclosed for a period of about 10 minutes and the finger blood flow observations continued.

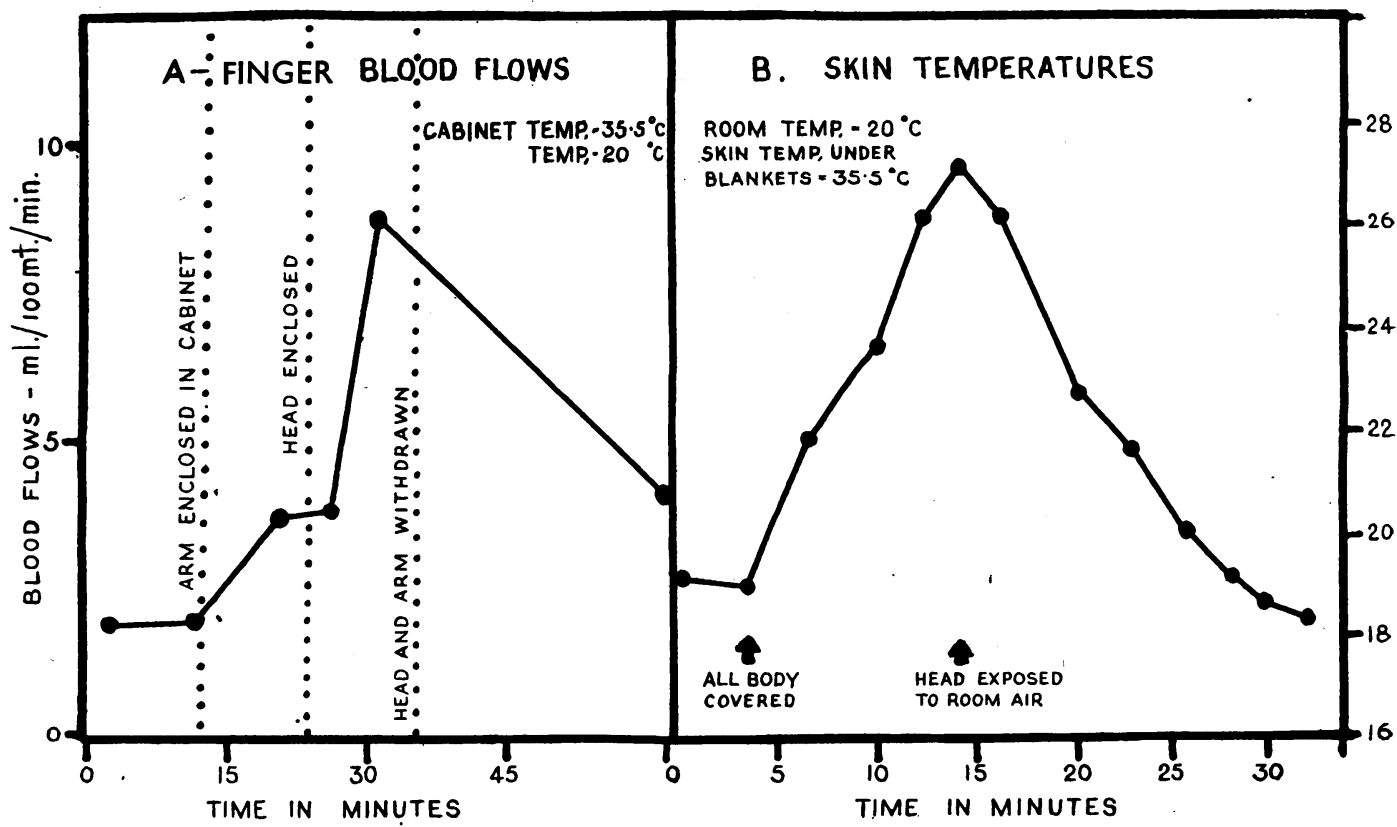

FIG. 2.-Cold hypersensitivity. The effect of exposing different areas of body to cold stimulus. (A) Blood flows. Subject seated in cabinet at $35 \cdot 5^{\circ} \mathrm{C}$. (B) Skin temperatures. Subject in room at $20^{\circ} \mathrm{C}$. covered with blankets.

No rise in rectal temperature occurred, yet a considerable increase was recorded in finger blood flow.

On withdrawing the head and arm from the cabinet the finger blood flow fell again. It seemed, therefore, that the persistent vasoconstrictor tone was due to an abnormal sensitivity to cold-the exposure of the head, neck and arm to a temperature of $20^{\circ} \mathrm{C}$. being sufficient to maintain a considerable degree of vasoconstriction.

The Role of the Sympathetic Nerves in Cold Hypersensitivity._-Sympathectomy was carried out in two cases of Raynaud's disease and one of acrocyanosis. Typical delayed dilatation in response to rising cabinet temperatures was recorded in all pre-operatively. The case of Raynaud's disease shown in Fig. 3 was investigated further before operation and shown to be " cold hypersensitive." Thus, with the cabinet at $36^{\circ} \mathrm{C}$., enclosing all the body, including head and right arm, produced vasodilatation in the right hand. Vasoconstriction followed exposure of the face alone to the cold of the room. After preganglionic cervical sympathectomy the patient, examined daily during a period of three weeks, showed no evidence of " cold hypersensitivity," nor did intensive body heating produce vasodilatation. Similar results were obtained in all three cases. 


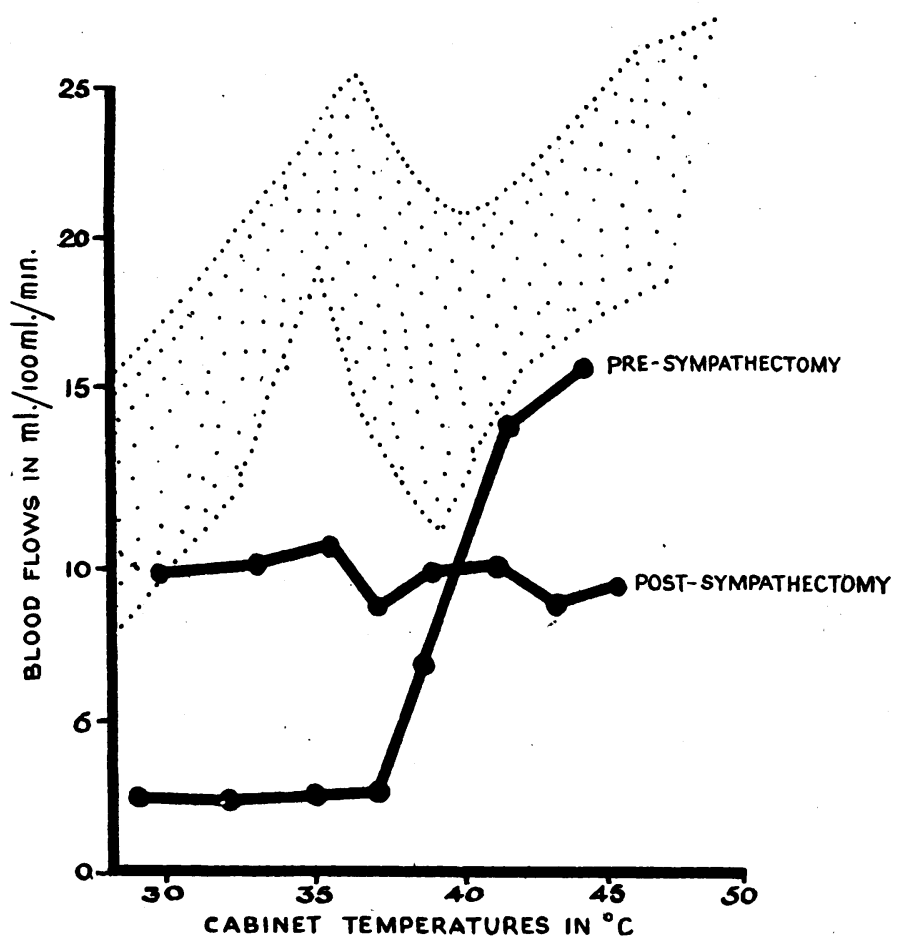

FIG. 3.-The effect of sympathectomy on delayed vasodilatation in a case of Raynaud's disease. Shaded area shows limits of normal for the series (air-filled plethysmograph).

\section{" Cold Hypersensitivity" Demonstrated by the Skin Temperature Method}

In 40 experiments already referred to, "cold stimulus" was removed from the surface of the body by covering with blankets. In most subjects, when all the body, including the head and neck, was covered, the skin temperature of the index finger (which alone remained exposed to the room) rose to about $35^{\circ} \mathrm{C}$. with no change in rectal temperature (Table II). Exposing different parts of the body's surface to temperatures below or above body temperature caused cutaneous vasoconstriction (Fig. 4 and 5). Exposing the head and right arm to the room air at $20^{\circ} \mathrm{C}$. thus usually

TABLE II

Normal Subjects-Skin Temperature Changes on Removing " Cold StIMULUs"

\begin{tabular}{|c|c|c|c|}
\hline & \multicolumn{3}{|c|}{ Skin Temperatures ${ }^{\circ} \mathrm{C}$. } \\
\hline $\begin{array}{c}\text { Rectal } \\
\text { temperature } \\
{ }^{\circ} \mathrm{C} .\end{array}$ & $\begin{array}{l}\text { Body } \\
\text { completely } \\
\text { covered }\end{array}$ & $\begin{array}{l}\text { Head and Neck } \\
\text { exposed to } \\
\text { room at } 29^{\circ} \mathrm{C} \text {. }\end{array}$ & $\begin{array}{c}\text { All body } \\
\text { exposed to } \\
\text { room at } 20^{\circ} \mathrm{C} \text {. }\end{array}$ \\
\hline $\begin{array}{l}37 \cdot 2 \\
37 \cdot 2 \\
36 \cdot 9 \\
37 \cdot 1 \\
37 \cdot 1 \\
37 \cdot 1 \\
37 \cdot 0 \\
37 \cdot 1 \\
37 \cdot 0 \\
37 \cdot 1\end{array}$ & $\begin{array}{c}\overline{36 \cdot 1} \\
35 \cdot 2 \\
34 \cdot 9 \\
- \\
\overline{-} \\
\overline{-} \\
35 \cdot 0 \\
34 \cdot 8\end{array}$ & $\begin{array}{l}32 \cdot 0 \\
33 \cdot 5 \\
32 \cdot 2 \\
32 \cdot 5 \\
33 \cdot 0 \\
31 \cdot 0 \\
32.4 \\
34 \cdot 0 \\
33 \cdot 0 \\
33 \cdot 1\end{array}$ & $\begin{array}{l}23 \cdot 1 \\
27 \cdot 0 \\
19 \cdot 0 \\
19 \cdot 0 \\
22 \cdot 0 \\
23 \cdot 4 \\
31 \cdot 2 \\
29 \cdot 6 \\
25 \cdot 0 \\
25 \cdot 4\end{array}$ \\
\hline
\end{tabular}






FiG. 4.-The relation between body temperature and the response to cold stimulus. Skin temperature observations in the normal subject.

produced a fall in skin temperature of about $2^{\circ} \mathrm{C}$. In most subjects, therefore, covering all the body except the head and right arm raised the skin temperature of the index finger to maximum levels of $31^{\circ}$ to $33 \cdot 5^{\circ} \mathrm{C}$.

In four subjects, however, the same procedure failed to produce vasodilatation in the right index finger (Table III), even where the skin temperature of the abdomen under the blankets rose to $35 \cdot 4^{\circ} \mathrm{C}$. However, with the head and right arm also covered, vasodilatation was produced. In the case shown in Fig. $2 \mathrm{~B}$ the resting skin temperature was $19 \cdot 4^{\circ} \mathrm{C}$. rising on completely removing cold stimulus to $27 \cdot 5^{\circ} \mathrm{C}$., falling again on exposing the head alone to the cold of the room $\left(19^{\circ} \mathrm{C}\right.$.). Subsequent exposure of the whole body had no greater effect and it must be assumed that the vasoconstriction produced by exposure of the face alone was practically complete.

Each of the four subjects, investigated on a number of different occasions, gave similar results. In one, examined 7 times in a period of 4 months, the same findings were always obtained and the evidence indicates the presence of "cold hypersensitivity" similar to that previously shown in plethysmographic records with a heating cabinet.

In two of the cases there was a history of chilblains in childhood, otherwise there was no suggestion of abnormal sensitivity to cold. On examination, however, each of the cases showed a slight, diffuse or mottled purplish coloration in the skin of the hands, particularly on the dorsum. Expelling the blood from the skin by firm stroking was followed by a slow, sluggish return of colour. Otherwise no abnormalities were found. 
TABLE III

Cold Hypersensitive Subjects-Skin Temperature Changes on REMOVING "COLD STIMULUS"

\begin{tabular}{c|c|c|c}
\hline & \multicolumn{3}{|c}{ Skin Temperature ${ }^{\circ} \mathrm{C}}$. \\
\cline { 2 - 3 } $\begin{array}{c}\text { Rectal } \\
\text { temperature }\end{array}$ & $\begin{array}{c}\text { Body } \\
\text { completely } \\
\text { covered }\end{array}$ & $\begin{array}{c}\text { Head and neck } \\
\text { exposed to } \\
\text { room at 20 }\end{array}$ & $\begin{array}{c}\text { All body } \\
\text { exposed to } \\
\text { room at } 20^{\circ} \mathrm{C} .\end{array}$ \\
\hline 36.1 & 32.5 & $22 \cdot 8$ & 22.8 \\
36.1 & 30.5 & 19.4 & $19 \cdot 3$ \\
36.5 & 31.0 & 20.2 & 20.2 \\
36.1 & 28.5 & 21.4 & 21.6 \\
36.0 & 27.4 & 19.5 & 19.8 \\
36.3 & 26.8 & 21.2 & 21.0 \\
\hline
\end{tabular}

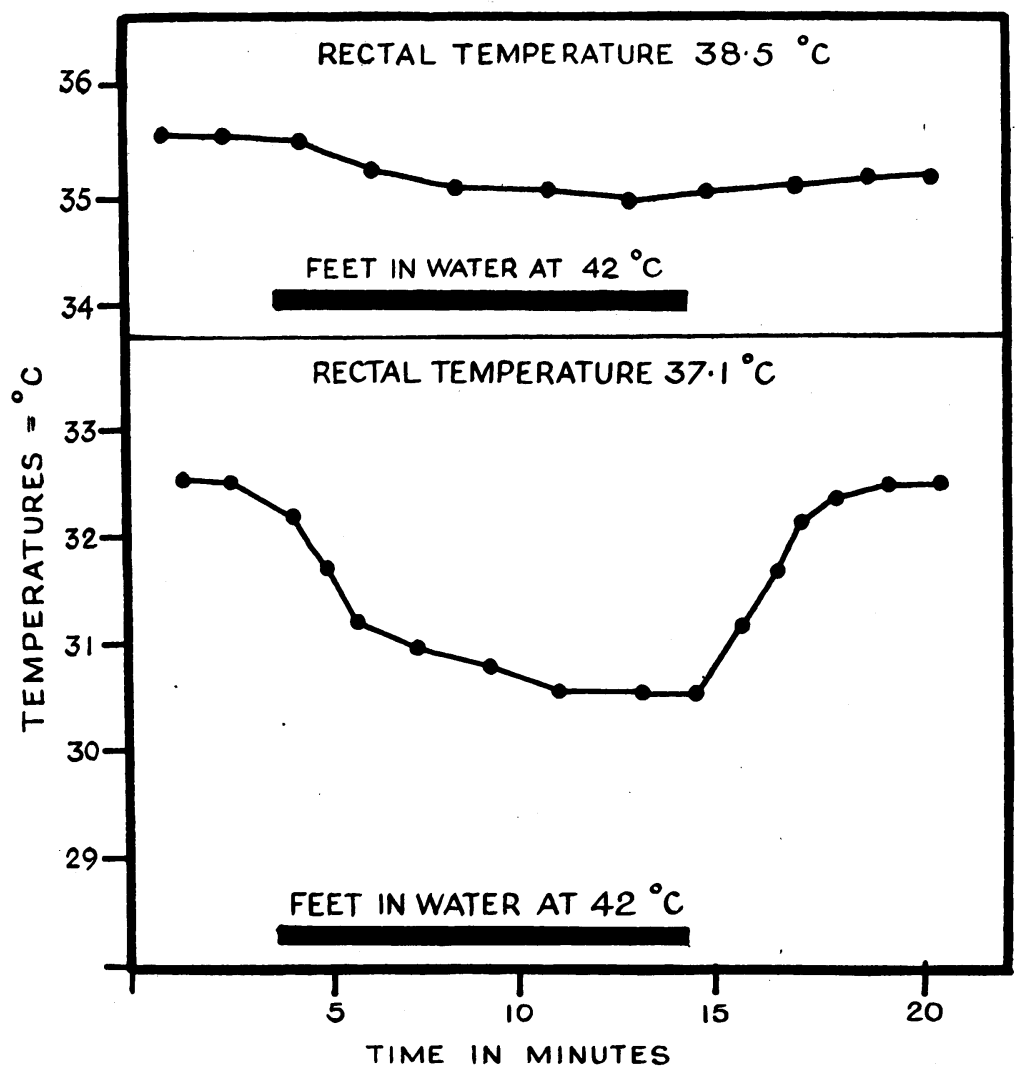

Fig. 5. - The effect of raising the body temperature on the response to heat stimulus. Skin temperature observations in the normal subject.

The Effect of “ Body Temperature” ON The Warmth and Cold Constrictor Responses

In order to throw additional light on the nature of the abnormalities described, the relation between " body temperature" and the sensitivity of the cold and warmth response was investigated in normal and "cold hypersensitive" subjects. Rectal and mouth temperatures were both measured thermoelectrically. The latter were unreliable, and the former were subject to slight variations related to the intestinal circulation (Grayson, 1950). However, as a record of relatively 
gross changes in internal temperature rectal records were regarded as the most satisfactory method available at the time.

The effect of rising environmental temperatures on the sensitivity of the cold and warmth vasoconstrictor reponses in normal subjects. Using the heating cabinet in the investigation of the normal subject, it was found that once the rectal temperature had risen, lowering the cabinet temperature produced no vasoconstriction in the hand until the rectal temperature itself returned to " normal " (Grayson, 1949).

This phenomenon was investigated further by the skin temperature method. In 6 experiments the body temperature of normal subjects was raised by covering the body with blankets and immersing the legs in hot water, and cold or warmth vasoconstrictor responses recorded at different rectal temperatures. In the case shown in Fig. 4 each observation was made with the body covered with blankets, except for the head and right arm. The cold constrictor stimulus used was the exposure of the anterior abdominal wall to the cold air of the room. Raising the rectal temperature from $36.9^{\circ}$ to $37.2^{\circ} \mathrm{C}$. produced a rise in skin temperature from $32.5^{\circ}$ to $33.7^{\circ} \mathrm{C}$. The intensity of the vasoconstrictor response was greatly diminished. When the rectal temperature had risen to $37.8^{\circ} \mathrm{C}$. the skin temperature rose to a fresh equilibrium level of $34.8^{\circ} \mathrm{C}$. The cold vasoconstrictor response was now entirely abolished.

The effect of heat stimulation was also investigated. In the experiment shown in Fig. 5 the subject was covered with blankets except for the head and right arm; the legs were immersed in water at $36^{\circ} \mathrm{C}$. during the resting periods. Heat stimulation was produced by transferring the legs to a water bath thermostatically maintained at $42^{\circ} \mathrm{C}$. and stirred continuously. Again, the heat constrictor response was reduced in intensity by small increases in rectal temperature, and abolished in the presence of high rectal temperatures.

Similar results were obtained in all cases. Although the methods used were not strictly quantitative, it is clear that in normal subjects raising the rectal temperature inhibited the cold and warmth vasoconstrictor responses.

Rising Body Temperature in Cold Hypersensitive Subjects. The effect of body temperature variations was studied in four cold hypersensitive subjects (Table III). In these, the average of 6 resting rectal temperatures measured on different days was $36.2^{\circ} \mathrm{C}$. In a group of 10 normal subjects the average resting rectal temperature measured under the same conditions was $37 \cdot 1^{\circ} \mathrm{C}$. (Table II). Statistical examination shows a significant difference between the two groups $(t=12 \cdot 500$; $\mathbf{P}=0.001$ ) the rectal temperatures of the cold hypersensitive subjects being lower than those of the normal subjects.

Experiments were performed in which the effect of raising the rectal temperature of the subjects was investigated. A cold hypersensitive subject was covered with blankets except for the head and right arm (Fig. 6). At the beginning of the experiment the rectal temperature was $36 \cdot 5^{\circ} \mathrm{C}$. and the resting skin temperature remained at $23.6^{\circ} \mathrm{C}$. despite a rise in temperature under the blankets of $35.2^{\circ} \mathrm{C}$. The rectal temperature was raised to $36.9^{\circ} \mathrm{C}$. by immersing the legs in hot water at $45^{\circ} \mathrm{C}$., when the skin temperature of the index finger rose to $32.5^{\circ} \mathrm{C}$. Exposure of the abdominal wall to the room air now produced a normal cold constrictor response. The rectal temperature was raised still further to $37.4^{\circ} \mathrm{C}$, the skin temperature now rose to $34^{\circ} \mathrm{C}$. Exposure of the abdominal wall now had no vasoconstrictor effect.

The experiment was repeated on another subject with similar results. Thus in cold hypersensitive subjects, when the rectal temperature was within the range of normality the cold vasoconstrictor effect was normal. When it was still higher, the cold vasoconstrictor response of the cold hypersensitive subjects was completely inhibited.

\section{Discussion}

Previous investigations have shown that rising environmental temperatures can produce rapid vasodilatation in the skin even when the rectal temperature is falling (Cooper and Kerslake, 1949 ; 
Grayson, 1949). Under the experimental conditions of the present investigation, however, a welldefined group of subjects has been found who do not respond quickly to changes in environmental temperature, but only produce full vasodilatation after the body temperature has risen. This group included several subjects with no clinical signs of circulatory abnormality and some who, whilst not requiring clinical treatment, showed signs of exaggerated circulatory sensitivity to cold; it also included several with frank pathological involvement of the peripheral circulation.

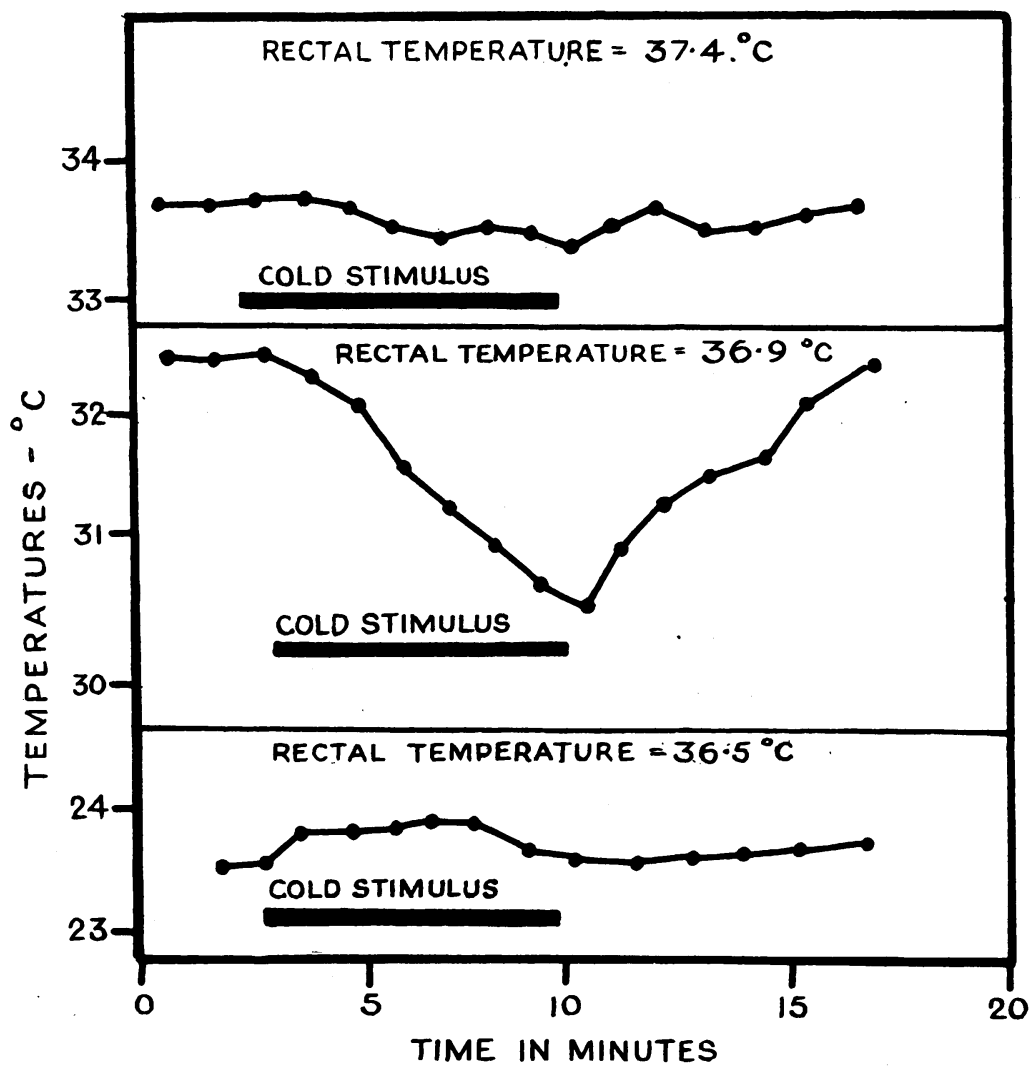

FIG. 6.-Cold hypersensitivity. The effect of raising the body temperature on the response to cold stimulus. Skin temperature records in cold hypersensitive subject.

The evidence available indicates that these abnormal findings depend on the experimental conditions. Thus they were only obtained when the head and neck and upper arm of the subjects were exposed to the cold of the room. When the whole of the subject was enclosed in the cabinet or covered with blankets, the abnormal constrictor tone was abolished. On the other hand, where the plethysmograph was used, the local temperature of the hand appeared to have little effect on the result. It may be concluded, therefore, that there is present in these subjects a state of cold hypersensitivity in which exposure of the head, neck and upper arm to temperatures of $20^{\circ} \mathrm{C}$. - the room temperature-is sufficient to maintain a considerable degree of vasoconstrictor tone, even when the rest of the body is exposed to temperatures as high as $40^{\circ} \mathrm{C}$.

Experiments before and after preganglionic cervical sympathectomy indicate, moreover, that this cold hypersensitivity depends on the integrity of the sympathetic innervation of the vessels. It would seem that there is some overactivity of the cold constrictor reflex.

The standards of cold hypersensitivity investigated in this way are purely arbitrary. It might be expected that if more of the body were exposed to cold as a routine, a higher percentage of cold 
hypersensitive subjects would be found. Indeed, when subjects were heated in a cabinet leaving the extremities and head and neck exposed to the room, Lewis and Pickering (1931) showed that vasodilatation never occurred until after the rectal temperature had risen. It could be argued that, under these conditions, sufficient of the body surface is exposed to the relative cold of the room to maintain a high degree of vasomotor tone even in normal subjects.

The phenomenon of " cold hypersensitivity" cannot be understood further without considering the relation between body temperature and normal cold and warmth vasoconstrictor responses. Body temperature in itself has a profound effect on the skin circulation (Pickering, 1932). Thus, raising the body temperature produced vasodilatation, lowering the body temperature vasoconstriction, irrespective of external cold or heat stimulus. But it is also clear that body temperature equally affects the sensitivity of the cold and warmth vasoconstrictor responses. Thus these effects are diminished in intensity or even totally inhibited in the presence of high rectal temperatures.

These experiments suggest that " cold hypersensitivity" in subjects at rest may also be a function of body temperature: it may be significant that the rectal temperature is significantly lower in them than in normal subjects. Moreover, "cold hypersensitivity" can be abolished by raising the rectal temperature, and it is clear that the reflex mechanism underlying cold vasoconstriction is just as subservient to general body temperature in cold hypersensitive as in normal subjects.

It is premature to speculate on the possible role of "cold hypersensitivity" as a predisposing factor in peripheral vascular disease, but it is worthy of note that the five vasopastic cases examined all manifested this abnormality.

\section{SUMMARY}

Venous occlusion plethysmography and skin temperature measurements were used to detect skin blood flow changes in human subjects.

Stimulus of cold was removed from the surface of the body either by means of a heating cabinet warmed to $36^{\circ} \mathrm{C}$. or by covering the subject with blankets.

Removing cold stimulus produced considerable skin vasodilatation in normal subjects without significant change in rectal temperature.

Subsequent exposure to temperatures hotter or colder than the body causes reflex vasoconstriction in the skin. The response is diminished or abolished by high rectal temperatures.

In some apparently healthy men, the cold vasoconstrictor responses are exaggerated under the usual resting conditions. The resting rectal temperature of subjects in this group is significantly lower than that of normal subjects. Moreover, raising the rectal temperature abolished "cold hypersensitivity." "Cold hypersensitivity" has been found in a few cases of Raynaud's disease and acrocyanosis.

Much of this work was done with the aid of a B.M.A. research scholarship. The author is also indebted to Professor F. H. Bentley for his collaboration and the provision of clinical material, and to Professor R. J. Brocklehurst for help and advice.

\section{REFERENCES}

Cooper, K. E., and Kerslake, K. McK. (1949). J. Physiol.; 108, 40.

Grayson, J. (1949). Ibid., 109, 53.

(1950). Ibid. (In the press.)

Lewis, T. (1936). Vascular Disorders of the Limbs. McMillan.

, and Pickering, G. W. (1931). Heart, 16, 33.

Pickering, G. W. (1932). Heart, 16, 115.

Schmidt, C. F., and Pierson, J. C. (1934). Amer. J. Physiol., 108, 241 